\title{
Formato Participatório: vias do envolvimento no processo criativo
}

Participatory format: routes of the involvement in the creative process

Maicyra Teles Leão e Silva ${ }^{1}$ 


\section{Resumo}

O texto aborda relações e tensões entre o contexto sócio-político contemporâneo e tendências participativas de criação na Arte, num viés liminar entre as Artes Cênicas e Visuais, discutindo inicialmente o aspecto da inclusão social enquanto prerrogativa de engajamento crítico. Para tanto estabelece paralelos entre discussões do âmbito internacional e nacional, questionando, o envolvimento do Outro em projetos artísticos como transformação social, a priori. Assim, trata a participação como opção poética, com enfoque no formato do processo criativo, sugerindo o termo participatório como alternativa de localização dessa escolha. Ainda, explora a noção de participação de forma a apresentar modalidades de sua ocorrência no campo da Arte.

Palavras-chave: Participação em arte; inclusão social; formato de processo criativo; participatório

\section{Abstract}

This paper discusses relations and tensions between the contemporary socio-political context and participatory trends in Art, in an injunction bias between the Performing and Visual Arts. Initially discusses the aspect of social inclusion as critical engagement prerogative. For that, draws parallels between the international and national productions, questioning the involvement of the Other in Art projects and social transformation, a priori. So, it considers participation as a poetic option, focusing on the creative process format, suggesting the term participatory as an alternative location for that choice. Also explores the notion of participation in order to present modalities to its occurrence in Art field.

Keywords: Participation in art; social inclusion; creative process design; participatory

${ }_{1}$ Professora Adjunta do Núcleo de Teatro da Universidade Federal de Sergipe, doutora pelo Programa de Pós Graduação em Artes Cênicas da Universidade Federal da Bahia, Coordenadora do Grupo de Pesquisa Arte, Diversidade e Contemporaneidade - CNPq/UFS e integrante do GIPE-CIT/UFBA. 
A maioria criou um academicismo dessa relação ou da ideia de participação do espectador, a ponto de me deixar em dúvida sobre a própria ideia.

Hélio Oiticica (carta para Lygia Clark)

Quando falamos em Arte Participativa, no Ocidente, especialmente no Brasil, nos remetemos a um período histórico entremeado por questões políticas efervescentes, como meados do século XX. Tratar da participação requerida pelo Movimento Neoconcreto ou pelo Teatro Engajado de grupos como o Arena, por exemplo, é também tocar em aspectos ebulitivos relacionados a movimentos internacionais de emancipação social, como o feminismo ou como os movimentos estudantis e de contracultura, como também reportar a reverberações de uma política desenvolvimentista da década de 1950, com promessas acerca de uma reforma agrária e valorização popular, posteriormente agregada às reações advindas de restrições diretas impostas por uma Ditadura Militar.

Não sendo relevante para este artigo adentrar os meandros dessa efervescência política específica, vale-nos por ora confirmar uma coligação entre a proposta de participação na arte e anseios políticos como democratização do acesso, des-alienação em relação ao capitalismo, miscigenação e reconhecimento de diversidades e inclusão social.

\section{Inclusão social}

A especialista Claire Bishop (2012) reconhece três momentos distintos na história do século XX em que considera que há uma "virada social" na Arte. Inicialmente aponta as vanguardas das primeiras décadas do século (Dadaísmo, Surrealismo, Futurismo) como movimentos que requeriam a ação participativa também em virtude dos efeitos de uma guerra de proporções mundiais; num segundo momento, menciona os efeitos pós segunda Grande Guerra que se manifestam desde as ações da Internacional Situacionista aos regimes repressores na América Latina; e, por último, a queda do regime comunista simbolizada pela derubada do Muro de Berlin, em 1989.

\footnotetext{
De uma perspectiva europeia ocidental, a virada social na arte contemporânea pode ser contextualizada por dois momentos históricos prévios, ambos sinônimos de agitações políticas e movimentos para transformações sociais: a histórica vanguarda europeia, por volta de 1917, e a então chamada 'nova' vanguarda, de 1968. O ressurgimento notável da arte participativa nos anos 90 me leva a acreditar que a queda do comunismo, em 1989, é um terceiro ponto de transformação [...] Cada fase veio acompanhada por um repensar utópico sobre a relação entre a arte e o social e o seu potencial político - manifestado através da reconsideração de caminhos pelos quais a arte é produzida, consumida e debatida² (Bishop, 2012, p. 3).
}

\footnotetext{
${ }^{2}$ [From a Western European perspective, the social turn in contemporary art can be contextualized by two previous historical moments, both synonymous with political upheaval and movements for social change: the historic avant-garde in Europe circa 1917, and the so-called 'neo'avantgarde leading 1968. The conspicuous resurgence of participatory art in the 1990s leads me to posit the fall of communism in 1989 as a third point of transformation [...]. Each phase has been accompanied by a utopian rethinking of art's relationship to the social and of its political potential - manifested in a reconsideration of the ways in which art is produced, consumed and debated]. (Tradução nossa).
} 
Apesar de especificar que o ponto de vista de onde parte é oeste-europeu, no Brasil podemos estabelecer paralelos claros com os períodos mencionados por ela, sendo, portanto, coerente a associação: a Semana de Arte de 22; os Movimentos Concreto e Neoconcreto entre 1960 e 1970, na época, submetidos à situação de ditadura militar; e a eclosão significativa de Coletivos de arte nos anos 1990, bem como as diferentes práticas de colaboração no teatro.

Ainda, o que ela chama de virada Social [social turn], inicialmente mencionada em artigo de 2006, está relacionado, portanto, a uma canalização da arte, praticada como materialidade e capital simbólico, em direção a uma transformação social, pelo menos enquanto intenção. Se por um lado, o tratamento social na arte está vinculado ao político na medida em que requer uma dimensão crítica da condição histórica vigente, as formas de manifestação desse envolvimento crítico-social variam tanto no que concerne a especificidades locais e poéticas, quanto a reações macroestruturais aos paradigmas da época.

$\mathrm{Na}$ apresentação de heranças da cena atual, a autora menciona como esboço referencial dos artistas envolvidos nessas práticas ${ }^{3}$ pensadores como Walter Benjamin, Paulo Freire, a Internacional Situacionista, Deleuze e Guattari e Hankim Bey, para lançar mão de uma rede ampliada de interlocuções.

Todavia, Bishop sustenta, como sua base teórica, uma linhagem de concepção marxista, especialmente amparada nas discussões do filósofo francês Jacques Rancière, o que implica numa discussão acirrada sobre os efeitos de determinados discursos políticos no sistema da arte e as ciladas embutidas num propósito ético dela como sendo uma atitude previamente entendida como politicamente correta. Dentre as discussões e problematizações levantadas pela pesquisadora, uma delas em especial é relevante para o desenvolvimento do pensamento que pretendo apoiar: a solução implícita no discurso da inclusão social no campo da arte, com efeitos como empoderamento e transformação cidadã, serve como mecanismo de amparo a uma macropolítica do bem-estar social, no entanto, não garante uma ruptura ou uma resistência no sentido estético.

Aspectos como respeito pelo Outro, reconhecimento de diferenças e proteção a liberdades contribuem para a crença da Arte como esperança e promessa de um mundo melhor, uma vez que encontra objetivos concretos e supostamente mais substantivos e "reais" do que a experiência estética em si. Por outro lado, o discurso crítico anti-capitalista, aceito como analogia tácita da inclusão do Outro, sugere uma equivalência automática como se essas fossem práticas de resistência e, nesse sentido, a quase inviabilidade crítica embutida nessas intenções é uma ameaça para sua própria existência democrática (Rancière, 2012), já que anula dissensos.

É também por meio desse tipo de defesa, que essa inclusão alcança, nos dias atuais, diversas formas perversas ${ }^{4}$ de mídia massiva, sendo empregada desde a colaboração via compartilhamento gratuito de vídeos pessoais, feitos por celulares, a grandes empresas lucrativas de telecomunicações a programas de entertainment veiculados como Reality Shows.

${ }^{3}$ Informação coletada a partir de respostas de artistas-coletivos sobre suas próprias influências, através de questionários aplicados pela obra What, How \& for Whom [O quê, como e para quem], do Collective Creativity, Kassel: Fridericianum/Frankfurt: Revolver, 2005, p. 344-346. 
Hoje em dia participação é utilizada por empresas como uma ferramenta para aprimorar eficiência e força de trabalho moral; é onipresente nos meios de comunicação das formas de televisão realista; e é também um meio privilegiado para fundações governamentais criarem a impressão da inclusão social ${ }^{5}$ (Bishop, 2006, s/p).

Deste modo, a participação e o envolvimento social não garantem o apelo político requerido por essas práticas artísticas, uma vez que não há receitas fixas sobre essa "boa arte" e nem sobre os efeitos éticos acoplados a ela. Do ponto de vista de uma crítica didática, assumir o politico como tema explícito (realismo político), como praticado de forma mais intensa em meados do século XX, afasta as ambiguidades geradas pelo realismo ético (Cornago, 2008), uma vez que se sustenta em questões relacionadas a conteúdo e não a modos como se fazer.

Deste modo, trato a participação como opção poética, desatrelada de um apelo como resistência política a um sistema macroestrutural, uma vez que me interessam as escolhas de formato vivenciadas e não, por ora, a eficácia delas decorrentes.

\section{Social e Arte}

Especificamente no campo teatral, compreendido como de crucial relevância para a investigação do encontro ao vivo, autores recentes como Hans-Thies Lehmann, Augusto Boal e um outro conjunto heterogêneo de pensadores relacionados à performance e à performatividade, há algumas décadas anteriores, apontam algumas características relevantes para a localização do envolvimento social como prática artística.

Primeiramente, ao analisar a conjuntura do teatro na contemporaneidade realizado na Europa, em seu livro de 1999, intitulado Teatro Pós-Dramático, Lehmann sugere uma diminuição da relevância da narrativa dramática, expressa pelo texto e concepção cênica, em favor de uma fragmentação, em diversas instâncias, dessa cena. Decorrente desse aspecto, em palestra ocorrida na cidade de Salvador-Bahia, em sua tournée pelo Brasil, 2010, apresenta seis tendências [termo utilizado pelo autor] do teatro contemporâneo, dentre as quais as duas primeiras se fazem necessárias no momento.

A primeira delas diz respeito ao uso de ferramentas colaborativas na construção da cena. Apesar de não especificar claramente o teor dessas estratégias, Lehmann menciona superficialmente algumas razões e consequências de sua utilização: o fortalecimento de um circuito independente; a utilização de espaços alternativos, já que se busca mover a cena em direção a "onde o público está" e o emprego de materiais biográficos para a construção da mesma.

Coligada a essa tendência, mas mencionada como uma segunda, encontra-se a interação entre teatro e sociedade, mais uma vez reforçada por aspectos políticos como a queda do muro de Berlin e os eventos de 11 de setembro, que por sua vez demandaram solidariedade em torno do econômico-social. Diante dessa tendência, o autor menciona como decorrência o Teatro Documentário e anuncia a utilização de atores não-profissionais na cena, o que chama de a nova politização do teatro.

Retomando aspectos das tendências, citadas acima, no Brasil, proposições como o Teatro do Oprimido - TO, fundado por Augusto Boal, a partir da década de 70 
e com maior visibilidade nos anos $1980 / 90^{6}$, parecem preconizar algumas matrizes de conexão com a discussão, obviamente por instaurar uma demanda de mudança social: "O nosso desejo é o de conhecer o mundo que habitamos, para que possamos transformá-lo da melhor maneira" (Boal, 2007, p. 11); assim como, por estabelecer estratégias inclusivas, como a utilização de não-atores na cena, no Teatro Fórum e Legislativo, por exemplo, e a expansão de locais e públicos apropriados para a realização dela. Como se tornou notório a seu respeito: "todos os seres humanos são atores, porque agem, e espectadores, porque observam. Somos espect-atores" (Boal, 2011, p. 11).

Como premissa básica, Boal defendia a apropriação da experiência de vida, consequentemente dotada de contradições e poderes da ordem do social, político, econômico e psicológico, como material narrativo e compartilhado da cena. Dessa forma, através do convite aberto e mediado pelos coringas ${ }^{7}$ à plateia, espect-atora, deveria intervir na cena com proposições e reflexões sobre o assunto apresentado. Apesar de existirem diferentes tipos de formato no TO, que concernem dessa estratégia central, o princípio pré-anuncia as ocorrências analisadas por Lehmann, acerca de uma nova politização no teatro, e apesar do aparente distanciamento geográfico reforça um outro aspecto: a disseminação em rede.

Associado a sua proposição estética, Boal tinha como objetivo a expansão de seu trabalho através da preparação de multiplicadores, que por sua vez além de aceitar e acreditar no TO, possuíam certa autonomia quanto aos meios de propagação da ação, gerando assim maior mobilidade à proposta.

É também na década de 90 que se registra no Brasil uma proliferação ${ }^{8}$ da existência de coletivos artísticos, que além de discutirem diretamente questões relacionadas ao mercado de arte e, portanto, também, à autoria e ao produto objectual, estabeleciam de um modo geral uma prática voltada ao urbano e suas implicações sociais e ambientais. Como espaço de circulação de suas ações, alguns desses coletivos se associaram temporária ou prolongadamente a cooperativas, comunidades/ vizinhanças específicas, movimentos sociais e ativistas ou mesmo se imbricaram na realização de eventos que viabilizassem o trânsito de suas "obras", ideias e, especialmente, promovessem mútuos encontros e trocas. Como afirma o curador Fernando Cocchiarale:

existe um ar comum nas intervenções propostas pelos jovens artistas brasileiros dessa passagem de milênio que os distingue e especifica em relação ao passado. O paradigma que atualmente empresta sentido a seus deslocamentos e conexões é o da rede. Não me refiro apenas aqui à rede eletrônica que hoje recobre todo o planeta $(2005$, p.17).

\footnotetext{
${ }^{6}$ Período em que há uma compilação estruturada de suas publicações, bem como, tradução de livros.

7 "O Coringa é uma personagem onisciente que altera, inverte, recoloca, pede para ser refeita sob outra perspectiva uma cena, sempre que sinta necessidade de alertar a platéia para algo significativo, concentrando a função crítica e distanciada." Verbete Sistema Coringa em Enciclopédia do Teatro - Itaú Cultural. Disponivel em http://enciclopedia.itaucultural.org.br/termo620/sistema-coringa. Acesso em 24 nov. 2013.

${ }^{8}$ Para maiores esclarecimentos sobre esse assunto, ver a dissertação de André Mesquita, intitulada "Insurgências Poéticas: arte ativista e ação coletiva"(2008), bem como textos produzidos por ocasião de eventos como o Spa das Artes (Recife-PE), Fora do Eixo (Brasília-DF), EIA (São Paulo-SP), SEU (Porto Alegre-RS), dentre outros.
} 
Sem me ater ao termo jovens artistas, o sentido de rede aqui reforça a comunhão de determinados valores ou perspectivas de ação, ao mesmo tempo em que mantém a lacuna da divergência, uma vez que não há nenhum tipo de manifesto comum declarado, solidificado. Por outro lado, afora proposições baseadas na livre circulação da obra, onde outros agentes a podem realizar mediante a autorização do artista, ou seja, não demandando a presença física do mesmo, muitos dos eventos, que viabilizaram a efetivação dessa rede, foram sustentados financeiramente por editais ou verbas estatais, inseridos numa conjuntura específica da política cultural brasileira, que acompanha a lógica da terceirização de serviços, através de editais.

\section{Participar}

Um desses coletivos que continua em ação desde a década de 90 é o Grupo de Pesquisa Corpos Informáticos (GPCl), fundado em 1992, na Universidade de Brasília, e coordenado pela professora e artista Bia Medeiros. Em suas publicações e práticas atuais, o grupo vem reforçando o caráter transgressor, ora jocoso ou aglutinador, de suas concepções, com referenciais conceituais próprios, como por exemplo em relação à própria linguagem a que se dedicam:

Corpos Informáticos não faz performance, faz fuleragem. Corpos Informáticos não faz intervenção urbana, faz composição urbana (e para rir utiliza a sigla de composição urbana: C.U.). A composição não intervém nem interfere na vida. Se a arte é vida, ela compõe e decompõe (Aquino; Medeiros; Mota, 2012, s/p).

Além da crítica embutida ao desgastado termo performance, o grupo convoca a um estreitamento da relação entre arte e vida, por sua vez também ressoante do percurso histórico citado anteriormente. Apesar de não desenvolver seus trabalhos com enfoque específico em comunidades ou algum aspecto social pontual, propõe um contato iterativo ${ }^{9}$ com o público, que se configura por uma relação em repetição, na qual cada repetição é permanentemente a causa da outra, compreendendo a obra como fruto dessa contaminação.

O fuleiro [aquele que pratica a fuleragem] age por iteração. A iteração é modo de existência e de compreensão de processos. Ela não é interativa, ela se repete, cada vez de forma diferente e permite que o outro modifique o que está dado, ou foi previsto (Aquino; Medeiros; Mota, 2012, s/p).

A esse agir com o Outro, compreendendo a obra como processo, ou mesmo o processo como produto, artistas de diferentes gerações e contextos vêm buscando apoiar-se no desenvolvimento de trabalhos que, de um modo geral, buscam incluir, para trocar. Apesar de serem termos (inclusão, troca) de polêmica latente, assim como bem discute Bishop, acerca do termo inclusão, uma vez que reforça e reproduz valores de um sistema capital imponente, eles servem para localizar o discurso a que se pretende com a arte participativa. Como indicado em slides organizados pelo artista Xavier Roux, cujo título é Participatory Art, a arte dita participativa tem como principal

${ }^{9}$ Referência citada pelo GCPI: G. Deleuze. Diferença e Repetição. Rio de Janeiro: Graal, 1988. 
objetivo o envolvimento do Outro (inicialmente, público/plateia e, agora, subjetividade alheia e diretamente ativa) no processo de concepção/realização da obra.

Essa proposição ilustra de maneira clara o que de fato pretende-se homogeneizar com o discurso da Arte Participativa, pré-concebida como eticamente correta e valorosa. Sem me estender na discussão sobre essa pré-concepção, amplamente levada a cabo por Bishop (2012), me interessa perceber como o campo de ação desloca-se para além do contexto interno à obra, entendida até então como peça ou objeto ou mesmo ação, também disposta à interatividade ( $\neq$ iteratividade), mas que ainda não envolve o público/pessoa como sendo a obra. Nesse sentido, sigamos traçando um percurso para facilitar o entendimento e a localização sobre a participação no contexto ampliado da obra, sem merecimentos de causa ou efeito histórico e sem coligações sequenciadas.

É também a partir da década de 1990, no Brasil que o termo Processo Colaborativo passa a ser bastante utilizado na área teatral, tendo como ícone de referência o grupo Teatro da Vertigem, conduzido por Antônio Araújo, em São Paulo. De forma sintética, o que se convencionou chamar de Processo Colaborativo, diz respeito a uma prática de colaboração, interna ao grupo, onde se busca amenizar hierarquias e individualidades autorais, por meio da interferência mútua das funções no processo de criação e concepção da obra. Dessa forma, por exemplo, o texto-base da peça ia sendo escrito de forma processual por um dramaturgo, que acompanhava improvisações realizadas por atores e direção, e vice-versa, num investimento profundo e extenso no exercício de pesquisa de linguagem artística, via colaboração horizontal. Assim, ao final, havia uma assinatura autoral em relação a cada função, mas estava explícito, diante do formato de processo, que havia uma inter-contaminação criativa permeando as funções. Nesse sentido, a colaboração estava centrada num compartilhamento interno ao grupo, que gerava por sua vez uma ampliação da noção sobre quem era criador na obra.

Dessa forma, se estabeleciam relações que promoviam uma disseminação da função coral na cena contemporânea, como apontam Jean-Pierre Sarrazac (2006) e Hans-Thies Lehmann (2007), que passaram a assumir esse título, processo colaborativo, numa clara tentativa de inventar um modo particular de fazer teatro, seja por vontade ou por força das suas circunstâncias de produção, capaz de "considerá-las como evidências consequentes de um teatro que encontra na incompletude o modo mais original de dizer a sua época" (Abreu, 2007). Essa incompletude repercutia inclusive no princípio agregador dessa forma de criação, como afirma Luís Alberto de Abreu, dramaturgo, professor e coordenador do Núcleo de Dramaturgia da Escola Livre de Santo André:

\footnotetext{
o "acordo" estabelecido não é um acordo de cavalheiros. É um acordo tenso, precário, sujeito, muitas vezes, a constantes reavaliações durante o percurso. Confrontação (de ideias e material criativo) e acordo são pedras angulares no processo colaborativo (Abreu, 2003, p. 4).
}

Saltando para a primeira década do século XXI, apesar de coexistirem experiências que se autodesignam tanto como uma obra relacional, quanto como um processo colaborativo, no sentido da afiliação exata do termo ao conceito, algumas 
experiências começam a despontar como poéticas que se situam em uma zona de indiscernibilidade, mas que, no entanto, utilizam a premissa colaborativa, num misto de experiência relacional, convivial, com estruturação pré-configurada do envolvimento do Outro.

\section{Arte Participatória}

Termos como interação, interatividade, cooperação e colaboração despontam como palavras-chaves dessas poéticas, que por outro lado se denominam como Arte Socialmente Engajada, Arte Aplicada, Artivismo, Arte Participativa, Arte Dialógica, Performance no Campo Expandido, Novo Gênero de Arte Pública, dentre outros, cada qual se definindo de forma fluida e com escalas diferenciadas de penetração social.

De um modo geral, essas práticas buscam romper a auto-referencialidade do discurso artístico, incorporando a prática social como meio para alcançar esse deslocamento, e propõem uma mudança na percepção estética no sentido que deslocam a atenção da arte pautada no visual e sensorial para o discurso e a negociação.

Além disso, a localização entre disciplinas de conhecimento é também instrumento para alcance dessa quebra de referencialidade, como nos mostra o pesquisador mexicano Pablo Helguera:

Artistas que querem trabalhar com comunidades, por qualquer que sejam os mo-
tivos, podem se beneficiar dos conhecimentos acumulados por várias outras dis-
ciplinas - como sociologia, educação, linguística e etnografia - para promover
decisões sobre como envolver e construir trocas e experiências significativas. O
Objetivo não é se tornar etnógrafos, sociólogos ou educadores amadores, mas
entender as complexidades dos campos que vieram anteriormente, aprender algu-
mas de suas ferramentas e empregá-las no fértil território da arte ${ }^{10}(2011$, p. XIV).

Essas intersecções aparecem em projetos participativos com diferentes intensidades e propósitos, e realçam o campo liminar onde pretendem se dispor.

Seguindo, longe de querer demonstrar divisões rigorosas entre essas denominações ou entre essas qualidades de participação, buscarei tecer comentários sobre essas qualidades de envolvimento para gerar texturas nessas dimensões e facilitar a compreensão do que se busca com o participatório.

Primeiramente, estar em interação pode ser entendido como instância cotidiana inerente ao contato e, dessa forma, situar-se num mesmo ambiente poderia se caracterizar como interagir. Por outro lado, o sentido do ser afetado e contaminar e ser influenciado por uma ação requer mutualidade, uma vez que a disponibilidade subjetiva é necessária em situação de i(n)teratividade. Como descreve o Corpos Informáticos, já citado, "a iteração é modo de existência e de compreensão de processos. Ela não é interativa, ela se repete, cada vez de forma diferente e permite que o outro modifique o que está dado, ou foi previsto (Aquino; Medeiros; Mota, 2012, p. 2 - 6). A diferença entre iteração e interação, demarcada pelo grupo, evidencia o tipo de

\footnotetext{
${ }^{10}$ [Artists who wish to work with communities, for whatever reason, can greatly benefit from the knowledge accumulated by various disciplines such as sociology, education, linguistics, and ethnography - to make informed decisions about how to engage and construct meaningful exchanges and experiences. The objective is not to turn us into amateur ethnographers, sociologists, or educators but to understand the complexities of the fields that have come before us, learn some of their tools, and employ them in the fertile territory of art]. (Tradução da autora).
} 
envolvimento requerido por essa possibilidade de agir e modificar o que está posto e, nesse sentido, o mero contato entre indivíduos não caracterizaria propriamente a interação já que "para olhar (regarder) é preciso estar disponível" (Stiegler, 2007, p. 45).

Partindo, então, desta premissa de disponibilidade para o vínculo da interatividade, aspecto primordial para a vontade participativa, Helguera $(2011, p .16)$ estabelece 3 tipos de pré-disposição para a participação: voluntária, quando há um envolvimento ativo e pronto; não-voluntária, quando há uma coerção ou uma imposição para o engajamento; e involuntária, quando há um envolvimento pautado na causalidade do encontro, sem nenhum tipo de esclarecimento sobre a situação de confluência. $A$ configuração deste tipo de participação se modifica a cada natureza de projeto, mas nos ajuda a localizar duas instâncias que precisam ser distinguidas: a participação como envolvimento direto do espectador no acontecimento artístico e a participação como material processual de construção do evento artístico.

Se considerarmos exclusivamente o evento ao vivo, retomando a ideia de feedback looping anunciada por Fischer-Lichte (2008), essa interação seria a base para o estabelecimento da qualidade performativa, já que a partir desse retorno mútuo que a condição de presença é estabelecida.

Em performance de um modo geral (e não apenas a partir dos anos 1960), os espectadores não estão distanciados do evento ao gerar significado, mas sim agem como participantes envolvidos. Mesmo quando alguns espectadores se distanciam de forma ostensiva se reclinando em suas poltronas ou fazendo comentários desdenhosos em voz alta, eles ainda continuam a participar e influenciar o feedback looping da autopoiesis ${ }^{11}$ (Fischer-Lichte, 2008, p.183).

Por outro lado, a ideia de feedback elucida a interação como base para o compartilhamento de co-presenças, mas não examina como essa participação pode ser modelada por diferentes estruturas e camadas de interação.

Helguera (2011 ,p.14 -15), por outro lado, sugere uma taxonomia baseada em quatro tipos, quando esse espectador é envolvido por diferentes intensidades. Ele indica primeiramente a participação nominal, ou seja, aquela em que o espectador é convidado a apenas apreciar a obra, mas de modo ativo e reflexivo, o que poderia ser exemplificado pelo trabalho do artista espanhol Antoni Muntadas, exposto como um aviso, desde 1996, com a seguinte mensagem: Atenção: Percepção Requer Participação.

Seguindo com Helguera, outro modo de estruturação desse envolvimento seria a participação direcionada, na qual o espectador completa uma tarefa simples sugerida pelo artista, como no trabalho Árvore do Desejo, de Yoko Ono, 1996, em que sugere que os visitantes escrevam seus desejos em papéis e os coloque em uma árvore.

Em terceiro, propõe a participação criativa, em que o espectador é convidado a contribuir com algum tipo de conteúdo diretamente relacionado à estruturação do trabalho, o que pode ser exemplificado por trabalhos relacionados à Matchs de

\footnotetext{
${ }^{11}$ [In performance generally (and not just since the 1960s), spectators are not distanced from the event when generating meaning but rather act as involved participants. Even if some spectators ostensibly distance themselves from the performance by reclining in their seats in boredom or making loud scornful comments, they nonetheless continue to participate and influence the feedback loop's autopoiesis]. (Tradução nossa).
} 
Improvisação ${ }^{12}$, por exemplo, em que há uma estruturação do evento, mas o público é quem gera o conteúdo dramatúrgico da cena, ou mesmo o exemplo já citado de Retrospectiva.

E, por último, indica a participação colaborativa, em que há o compartilhamento de responsabilidades no desenvolvimento da estrutura e conteúdo do trabalho, com diálogo direto com o artista. Este último, se aproxima melhor da proposta de Participatório, no sentido em que apresenta aberturas que apontam para a criação em processo e não exatamente para o evento ao vivo.

Como complemento a esses modos, vale ainda adicionar uma modalidade de participação relacionada a uma disposição lúdica, muito próxima à ideia de jogo ou de happening, em que há uma condução ou um estímulo sensorial inicial que desencadeia processos espontâneos e arbitrários de iteração, podendo ser exemplificada pelas fuleragens do Corpos Informáticos e por diversas performances realizadas no espaço público.

Destarte, o último modo de participação proposto por Helguera aponta para uma participação em que há uma troca de fato negociada e dialogada, durante o processo de criação dessa obra, anterior ao evento ao vivo, abrangendo escolhas, seleções, eleições, convites, ambos pautados no estabelecimento de uma comunidade temporária a ser formada para fins de realização do projeto. Essa comunidade diferencia-se da noção de grupo como vivenciado por Processos Colaborativos em teatro e da noção de Coletivo Artístico, uma vez que se expande para além do núcleo formador profissional, se construindo a partir da relação com agentes externos.

Essa experiência de comunidade, por sua vez, configura diferentes modos de ação artística variando desde a compreensão, já citada, do Artivismo, em que há um envolvimento intenso no sentido de transformação político-social das questões comunitárias, a um envolvimento engajado numa causa específica, associada ao âmbito artístico, como em propostas denominadas Arte Socialmente Engajada ou Aplicada. Essas intensidades são mediadas, sem dosagens pré-estabelecidas, por diferentes tempos de dedicação ao envolvimento, bem como por distintos propósitos, ficando a critério do realizador como nomeá-la.

Do ponto de vista do que proponho como Participatório, que apresento mais detalhadamente adiante, não há pretensões no sentido de transformação ou intervenção social. Ele se configura mais como laboratório de investigação de modos de sociabilidade do que como esperança concreta. Assim, há um investimento duracional relacionado ao modo como se pretende dispor essa participação colaborativa, enquanto constituição de comunidade. Ou seja, não há uma medição de sucesso, quanto à pesquisa laboratorial, porque não há conquistas previstas. Certamente, o envolvimento não se pretende impune, mas não se almeja atingir metas específicas quanto à transformação social dessa comunidade. Afetos de fato são gerados, inevi-

\footnotetext{
${ }^{12}$ De forma sucinta, o Match de Improvisação é uma modalidade teatral baseada no improviso ao vivo, cujas cenas são criadas na presença dos espectadores, a partir de títulos sugeridos pela platéia. A modalidade foi criada no Canadá e busca uma aproximação entre o Teatro e 0 Esporte, no sentido em que está baseada numa estruturação fixa de times competidores, bem como a partir de um conjunto de regras que evidencia 0 universo cômico-lírico da competição, a dramaturgia criada pelo desempenho do ator, além da improvisação como espetáculo a partir dessa interação com a platéia. Para maiores informações ver trabalhos da pesquisadora brasileira Mariana Muniz e do fundador do Teatro-Esporte Keith Johnstone.
} 
tável à situação de colaboração, e contradições geradas pelas diferenças são postas à mostra como medida poética.

Assim, a palavra laboratório e o sufixo latino "-tório", que indica, no geral, um local apropriado para a atividade designada no verbo, como por exemplo em "consultório", local de consultas, quando associado a "participar" ganha um sentido misto, duplo. Etimologicamente, seria o local da participação, verbo que por sua vez significa "ter ou tomar parte em; associar-se pelo pensamento ou pelo sentimento; compartilhar de algo" (Dicionário Michaelis). Logo, participatório indicaria uma situação disponibilizada ao compartilhamento e a associações. Ainda, considerando o termo laboratório como "lugar de trabalho e investigação científica" (Dicionário Michaelis), participatório assume uma dimensão de pesquisa, como busca compreensiva para o entendimento desse fenômeno, o compartilhar.

Instituir a participatividade como laboratorial implica em assumir a condição de pesquisa artística também como central para essas proposições. Nesse sentido, há um investimento na investigação de metodologias criativas, que favorece a aproximação dessas prática com outras disciplinas do conhecimento humano.

Do ponto de vista do tipo de interação requerida no Participatório, considerando que se trata de um envolvimento processual, ela inicia-se ou, pelo menos, torna-se voluntária. O desenvolvimento do projeto dá-se quando há o interesse entre ambos os envolvidos em estabelecer o vínculo do compartilhamento. Nesse sentido, a atividade de participar ganha uma conotação de apropriação da situação, ou seja, implica em que os participantes, também criadores da obra, tornem o processo como algo advindo de sua própria voz/expressão. De forma muito simplificada, a ideia de participatório sugere o reconhecimento de algo que o Eu não faria se estivesse só. Ainda, este Eu não está disposto de um ponto de vista dialógico entre o self e o coletivo, mas a partir de uma perspectiva em que esse Eu encontra alteridades postas em conjunto sob determinadas condições específicas, pautadas pela situação de participação.

Para expor de modo simples: o artista passa a ser concebido menos como um produtor individual de objetos discretos e mais como um colaborador e produtor de situações [grifo da autora]; a obra de arte como algo finito, portátil, produto comercializável é repensada como um projeto em andamento ou a longo prazo com um incerto início e fim; enquanto o público, previamente era concebido como um 'espectador' ou 'observador', agora é reposicionado como um co-produtor ou participante (Bishop, 2012, p. 02). ${ }^{13}$

Ao sugerir a colaboração como elemento dessas práticas, Bishop convoca ainda, artistas e participantes, a uma cooperação para a realização do projeto, concordando com a ilustração dada pela definição de dicionário do termo: "trabalhar em comum com outrem na mesma obra" (Dicionário Michaelis). Deste modo, participar envolve colaborar, e vice-versa, mas ambos resguardam suas diferenças já que colaborar não designa necessariamente o ato de "tomar parte de/em algo". Como já mencionado anteriormente, se considerarmos o Processo Colaborativo, por exemplo, percebe-

${ }^{13}$ [To out it simply: the artist is conceived less as an individual producer of discrete objects than as a collaborator and producer of situations; the work of art as a finite, portable, commodifiable product is reconceived as an ongoing or long-term project with an unclear beginning and end; while the audience, previously conceived as a 'viewer' or 'beholder', is now repositioned as a co-producer or participant]. (Tradução nossa). 
mos como as funções estabelecidas pelo grupo se mantêm coesas, mesmo resguardando as mutualidades.

\section{Formato}

Por outro lado, ao nos depararmos com a condição laboratorial dessa participação, verificamos que, apesar de uma insistência na colaboração criativa, existe ainda uma condução que rege a concepção geral do projeto. Ou seja, apesar das funções criativas estarem dispersas já que participantes e conceptor se misturam na função de criadores, preserva-se a função autoral pautada na(s) pessoa(s) que elabora(m) a proposta do projeto. A autoria se desloca da criação como desenvolvimento da obra para o planejamento de sua forma.

Ela [a forma] não é o simples efeito secundário de uma composição, como suporia uma estética formalista, e sim o princípio ativo de uma trajetória que se desenrola através de signos, objetos, formas, gestos. A forma da obra contemporânea vai além de sua forma material: ela é um elemento de ligação, um princípio de aglutinação dinâmica (Bourriaud, 2009, p.28-29).

Desta forma, a compreensão sobre a forma ganha uma amplitude relacionada à noção de Projeto, como arranjo que necessita de uma ligação por meio de uma concepção aglutinadora. Esse sentido de forma se aproxima, por outro lado, à discussão proposta por Rosalind Krauss (2000), acerca da condição atual da obra de arte contemporânea, na qual defende que há uma recursivity [recursividade] que ampara a estrutura geral do trabalho de arte, a partir do estabelecimento de determinadas regras internas a ele. Ela entende que a obra de arte, nessa era da condição dos pósmeios, incorpora valores modernistas enquanto especificidade de mídia, rigorosa e analítica, ao mesmo tempo em que são desconstrutivistas no sentido do reconhecimento de seu lugar no mundo e do efeito desse mundo sobre ela mesma.

Assim, utilizo o termo formato para elucidar a coligação entre o elemento da recursividade, proposto por Krauss, e a noção de forma da obra contemporânea, ilustrada por Bourriaud, apesar de entender que outros termos também poderiam acompanhar e traduzir a mesma ideia, como por exemplo "formações".

Observando as práticas artísticas contemporâneas, deveríamos falar mais em "formações" do que em "formas": ao contrário de um objeto fechado em si mesmo graças a um estilo e a uma assinatura, a arte atual mostra que só existe forma no encontro fortuito, na relação dinâmica de uma proposição artística com outras formações artísticas ou não (Bourriaud, 2009, p. 30).

Portanto, interessa-me explicitar que esse formato é disparador de um projeto poético e, dessa forma, desencadeia determinados planejamentos criativos que irão tomar forma, como matéria visível, a partir da participação dos agentes convidados. Assim, retornamos à noção de formatividade lançada por Pareyson:

Há arte quando o exprimir apresenta-se como um fazer, e o fazer é, ao mesmo tempo, um exprimir, quando a formação de um conteúdo tem lugar como formação de uma matéria e a formação de uma matéria tem o sentido da formação de um conteúdo (Pareyson, 1997, p. 62). 
A formação do conteúdo é gerada ao mesmo tempo em que a formação da forma, mas o formato conceitual sugerido é o gatilho para a configuração dessa obra de arte. Assim, a noção laboratorial embutida no Participatório se afina à perspectiva processual já instaurada pelo formato escolhido como processo criativo.

Nesse sentido, o apelo socio-político requerido por essa modalidade artística, recae menos no discurso gerado e, mais, no posicionamento dado aos envolvidos no processo. A participação é conduzida pelo conceptor, autor, mas pode se apresentar como uma condução potencializadora, manipuladora, castradora desse agente participante. Deste modo, não há como pré-definir a condição ética e estética dessas produções, condicionadas à ação prática.

Para retomar e concluir, o sentido de inclusão social aparentemente mais coerente com essas práticas está relacionado ao contato e envolvimento do Outro no processo criativo, por meio de procedimentos e estratégias evidenciados pelo formato. Incluir, nesses casos, se refere então a um englobar essa subjetividade alheia para gerar diversidade de discurso criativo, sem propriamente requerer uma unidade harmônica. Colocar e dispor junto, com condução, sugere a instalação de um conjunto que não é unânime enquanto ideologia, comportamento, vontades, mas que, por isso mesmo, se apresenta potente enquanto evidência real de um determinado contexto.

\section{Referências}

ABREU, Luis Alberto. Processo colaborativo: relato e reflexões sobre uma ex periência de criação. In: Cadernos da Escola Livre de Teatro de Santo André, Ano I, Número 0, 2003.

AQUINO, F., MEDEIROS, M.B. de, MOTA, M. H. Corpos Informáticos: performance, corpo, política. In: Actas del I Encuentro Latinoamericano de Investigadores sobre Cuerpos y Corporalidades en las Culturas. Rosário: Red de Antropologia de y desde los cuerpos, 2012. Disponível em http://red.antropologiadelcuerpo. com/wp-content/uploads/MEDEIROS-MARIA-GT7.pdf. Acesso em: 22 dez. 2013.

BISHOP, Claire. Artificial Hells - Participatory art and the politics of spectator ship. London/New York: Verso, 2012.

Socially Engaged Art, Critics and Discontents. Entrevista concedida a Jennifer Roche. 2006. Disponível em: http://www.communityarts.net/readin groom/archivefiles/2006/07/socially_engage.php. Acesso em: 13 nov.13.

BOAL, Augusto. Jogos para atores e não atores. Rio de janeiro: Civilização Brasileira, 2007.

BOURRIAUD, Nicolas. Estética Relacional. São Paulo: Martins Fontes, 2009.

COCCHIARALE, Fernando. A (outra) Arte Contemporânea Brasileira: interven 
ções urbanas micropolíticas in: RIZOMA.NET. Artefato, 2005, p. 12-19. Disponível em: http://www.intervencaourbana.org/rizoma/rizoma_artefato.pdf, Acesso em: 19 nov. 2013.

Dicionário MICHAELIS. Disponível no link: http://michaelis.uol.com.br/moder no/portugues/. Acesso em 21/11/2013.

FISCHER-LICHTE, Erika. The transformative power of Performance: a new aes thetics. London: Routledge, 2008.

HELGUERA, Pablo. Education for Sociallz Engaged Art: a materials and techni ques handbook. New York: Jorge Pinto Books, 2011.

PAREYSON, Luigi. Os problemas da estética. São Paulo: Martins Fontes, 1997.

STIEGLER, Bernard. Reflexões (não) contemporâneas. Chapecó: Argos, 2007.

Recebido em 30/09/15

Aprovado em 30/ 05/ 16 